\title{
Healthcare-Seeking Behavior and Out-of-Pocket Payments in Rural Bangladesh: A Cross-Sectional Analysis
}

\author{
Muhammad Shahadat Hossain Siddiquee ${ }^{1, *}$, Amin Masud Ali ${ }^{2,3}$ \\ ${ }^{1}$ Department of Economics, University of Dhaka, Dhaka, Bangladesh \\ ${ }^{2}$ Global Development Institute, the University of Manchester, Manchester, UK \\ ${ }^{3}$ Department of Economics, Jahangirnagar University, Savar, Dhaka, Bangladesh \\ Email address: \\ shahadat_eco@yahoo.com (M. S. H. Siddiquee),aminmasudali@gmail.com (A. M. Ali) \\ ${ }^{*}$ Corresponding author
}

To cite this article:

Muhammad Shahadat Hossain Siddiquee, Amin Masud Ali. Healthcare-Seeking Behavior and Out-of-Pocket Payments in Rural Bangladesh: A Cross-Sectional Analysis. Psychology and Behavioral Sciences. Vol. 7, No. 3, 2018, pp. 45-55. doi: 10.11648/j.pbs.20180703.12

Received: July 25, 2018; Accepted: August 28, 2018; Published: September 28, 2018

\begin{abstract}
This study investigates the determinants of patient's choice of treatment (i.e., modern vs. alternative healthcare) using Bangladesh's Household Income and Expenditure Survey (HIES) dataset for exploring their healthcare-seeking behavior and the extent of out-of-pocket (OOP) payment due to illnesses. It explores this issues using the descriptive statistics, bivariate analysis like analysis of variance (ANOVA) and Chi-square test as well as econometric modeling (probit regression model on modern healthcare utilization for the full sample as well as for each quintile). All these help to identify the determinants of healthcare-seeking behavior in rural Bangladesh and how these vary across the quintiles of expenditure on food consumption. This study finds that higher percentage of healthcare-seeking patients receives alternative healthcare because of the lower cost and easier access compared to modern healthcare. The marginal effects of the predisposing factors like patient's age, parent's literacy, mother's age, house with separate dining room, access to electricity and mobile are significantly positive, which means these are more likely to influence modern healthcare utilization. In contrast, the marginal effects of the enabling factors like income, landholdings, access to social benefit are positive, but insignificant. Therefore, predisposing factors rather than enabling factors play crucial role in determining choice of modern treatment in rural Bangladesh. In addition, variations in the marginal effects exist across different groups based on regression by quintile. Finally, sickness prevalence as well as modern healthcare utilization also varies across geographic regions. The average OOP payment is higher for modern healthcare compared to alternative one and it remains true after disaggregation of OOP expenditure. Disease-specific OOP using firstdifference method is also positive for all diseases (i.e., OOP expenditure for modern healthcare> OOP expenditure for alternative healthcare) and most of the first-difference estimates are statistically significant. Similar tendencies are also observed in case of applying distributional analysis using quintiles. All these are important for formulating a national health policy for the rural people in Bangladesh. At last, a special attention to expanding utilization of modern healthcare is required for young mothers, elderly household head and the patients belong to minority group in rural Bangladesh.
\end{abstract}

Keywords: Healthcare-Seeking Behaviour, Predisposing and Enabling Factors, OOP, Rural Bangladesh

\section{Introduction}

Overall improvements in health require more efforts for the improvements in the utilization of modern healthcare as well as for the reducing healthcare inequalities in developing countries [1-4]. The extreme poor people in Bangladesh are excluded from the access to the existing essential healthcare package (ESP) due to four main barriers: information barrier, unfelt need, economic exclusion and social exclusion from health institutions [5]. Moreover, Bangladesh government has introduced user fee in 2009 at the public health facilities and such initiative has further limited the access to modern health facilities [6]. Recent data shows that physician density and nursing and midwife personnel density (both measured in per 1,000 population) is only 0.389 and 0.213 respectively [7], which clearly affirms the limited availability of modern health facilities in Bangladesh. This is much lower for the 
rural population in Bangladesh.

With a vision to provide healthcare services for all, government and NGOs have been expanding basic healthcare in rural Bangladesh over the last decade [8-10]. Though government has established extensive health infrastructure in each sub-district, people living in remote rural areas in Bangladesh are difficult to reach with essential modern healthcare [11-13]. In addition, concentrating only on accessibility of service does not produce favorable outcome of increasing the utilization of modern healthcare [14]. Therefore, socioeconomic and demographic factors that vary across sub-categories of population based on their poverty status cause variation in healthcare sought from modern practitioners. As utilization of modern healthcare is more prevalent among the richest segment of the population compared to the poorest one $[1,15,10-11,16,17]$, it is important to consider the influential factors like social structure, health beliefs and personal characteristics such as age, sex, religion and household characteristics of the users [18].

Predisposing factors including patient's age, parent's literacy, mother's age, house with separate dining room, access to electricity and mobile as well as the enabling factors including income, landholdings, access to social benefit play role in determining modern healthcare utilization [19-22]. The persistent inequality in income, education, ability to pay and access to modern healthcare facilities between the rich and poor in rural Bangladesh remind the differentials in healthcare-seeking behavior $[2,23]$. Inequality in the utilization of basic healthcare services put forward the need of addressing healthcare-seeking behavior of the disadvantaged populations for greater use of formal healthcare during their illnesses [15].

Remedial actions by patients for perceived ill-health are termed as healthcare-seeking behavior [24, 25], which depends on different external factors, health-beliefs and socio-economic conditions. In addition, revealed preference for treatment choice depends not only on illness type and severity but also on the pre-existing beliefs, accessibility to the available options and efficacy of the methods [26-28]. In developing countries treatment options are determined by poverty and gender to a great extent [29]. The existing treatment option in Bangladesh ranges from traditional spiritual or faith healer to modern western medicine. In remote rural areas, folk healers are popular in rural Bangladesh and they have the advantage over modern practitioners because of their capability of articulating and reinforcing the cultural values. They are also able to explain and treat patients based on the social, psychological and moral dimensions of ill-health $[30,14]$. The findings in the literatures concern the general problems related to healthcare-seeking behavior.

A number of studies have been conducted investigating the determinants of healthcare-seeking behavior. For example, authors $[11,31,16,32,18]$ have explored inequality in child and maternal healthcare-seeking behavior. Perry [33] has discussed the accessibility of primary healthcare. In addition, poverty status impacts healthcare-seeking behavior and treatment choice [34, 23, 12]. Last but not least, few studies $[14,15,35]$ have explored impact of health interventions on healthcare-seeking behavior. Education, accessibility and perception about the quality of the service among other also play an important role. However, these are not as much important as wealth [11]. In contrast, there exists gender biasness in healthcare-seeking behavior in Bangladesh and female seek less healthcare compared to their counterpart [15]. In Bangladesh influence of patriarchy, sub-ordinate position of women in the society and social, economic and religious forces which prevail in rural areas create the gender differentials and prevent women from perceiving their ill health as sufficiently important for seeking treatment [14]. Studies evaluating the health intervention programs claim those members who belong to the treatment group report less morbidity and more modern healthcare services compared to the non-members. These findings concern the specific problems placed in rural Bangladesh.

Studies have found that family size is one of the important factors for utilizing healthcare service. The larger the family size the less is the probability of utilizing modern healthcare service and this is due to higher financial constraints faced by the larger family size [36]. Level of education of the patient and the parents (especially the mother) is also found to be positively related to the use health services and choice of treatment $[37,38,14]$ as better educated persons and parents are more aware of their health problems, better informed about the availability of modern services and can use the information more efficiently [18, 39-40]. Gender of the patient is also another important determinant of treatment choice and the use of healthcare services. Gender inequality in health is a significant feature in most developing and poor income countries [41,7].

It is evident that previous literature considered limited factors, especially either for preventive or curative modern healthcare, and used small sample from a particular geographic area [11]. Therefore, previous studies suffer from the issue of generalization of their findings for the population. The impacts of different enabling, predisposing and need factors may vary across different heterogeneous income groups and across different heterogeneous regions. In this line of argument this particular study attempts to investigate the determinants of individual's choice of treatment (modern healthcare vs. alternative services) using nationally representative sample, which provide an idea about the healthcare-seeking behavior and the extent of outof-pocket payment of the whole rural population. This study makes an attempt to explore this issue by observing whether factors determining healthcare-seeking behavior vary across different quintile groups based on food consumption expenditure. The determinants used in this study include the socioeconomic, demographic and geographic factors that differentiate healthcare-seeking behavior in rural Bangladesh. This study aims to contribute in this regard by revealing and/or identifying the factors associated with healthcare sought from modern practitioners. 


\section{Analytical Framework}

The analytical framework used in this study is based on the behavioral model of healthcare-seeking developed by Anderson in 1960s. The different modern versions of Anderson's model have been applied in a number of recent studies [19, 42, 11]. As per Anderson's behavioral model healthcare-seeking behavior (both sought for service and treatment choice) depends on three set of individual characteristics - a) predisposing factors (i.e., sociodemographic characteristics such as age, sex, parents age, family size, level of education and literacy, household characteristics, access to mass media and health related attitudes) that reflect the issues that households with different characteristics have different propensity to use healthcare services, b) enabling factors (i.e., income, patient or parents are earner or not, wealth, access to safety net program, time to reach the provider etc.) which reflect the fact that individuals' needs and/or means to obtain the services and c) need factors that include type and severity of the disease, perception and knowledge about illness etc. These are the necessary conditions to seek healthcare services $[39,19,18]$. Based on the analytical model, this study aims to investigate the determinants of healthcare-seeking behavior mainly focusing on treatment choice by healthcare-seeking patients in rural Bangladesh and finds out whether the determinants influence treatment choice differently across the different groups by quintiles.

\section{Data and Methodology}

This cross-sectional study is based on Bangladesh Household Income and Expenditure Survey 2010, which is the latest publicly available dataset. It is conducted in every five years at household level covering the whole country. The study focuses only on rural setting. Out of total 12,400 sample households in HIES 2010, it is 7,840 households (which contain 35,894 individuals) that belong to rural setting. The survey questionnaire includes a section on health that collects self-reported morbidity with other relevant information like cost, time required, reason for choosing the provider etc. Self-reported morbidity is often criticized in the literature because of number of issues like inaccurate recall or individual's limited knowledge about illness experience [43]. To overcome or limit such errors the national questionnaire uses a limited recall period (30 days), culturally appropriate knowledge and adequate training to collect accurate and complete information. The survey also captures all relevant socioeconomic and demographic characteristics of the sample households.

Majority of the population live in rural Bangladesh and thus it considers only the rural patients seeking treatments during their illnesses. To investigate the determinants of patient's treatment choice, total sample size is 6,883 who sought treatment for their illnesses. As a part of methodology, descriptive statistics to econometric modeling (probit model on modern healthcare utilization for each quintile) have been used for identifying the determinants of healthcare-seeking behavior in rural Bangladesh. In addition, this study uses bivariate analysis (ANOVA and Chi-square test) to investigate treatment choice, treatment cost and how they vary across different illnesses. For probit analysis, a dummy dependent variable 'Modern' is used to treatment choice, where Modern =1, if healthcare is sought from modern practitioners and ' 0 ' for 'Alternative'. The former includes all allopath doctors and trained healthcare workers in government, private and NGO hospitals and clinics and the latter includes homeopath, ayurved/kabiraji/hekim, other traditional/spiritual/faith healers, family and self-treatment. This study also puts treatment/services from salesman of a pharmacy/dispensary into the second category as in Bangladesh salespeople or dispensers do not have any formal or informal training in dispensing drugs or in providing diagnoses and treatments [44].

A set of control variables has been chosen from the existing literatures, which show that treatment choice is related to the availability, cost and quality of the treatment, social structure, existing health beliefs and personal characteristics of the users [20-21, 37-38]. As per predisposing factors, we include patient's age, sex, household size, members per room etc. (i.e., demographic characteristics) and education and literacy of the patients and the parents, separate dining room for having meal, access to safe drinking water, proper sanitation, electricity and mass communication (i.e., socio-economic factors). This study uses food consumption expenditure to reflect the relative poverty status of the people living in rural areas in Bangladesh. Moreover, it evaluates how predisposing and enabling factors separately determine the treatment choice rather than using an index. As per this rationale and evidence from literature $[45,1]$, this study includes landholdings by the household, existence of separate dining room in the dwelling, earning status of the patient and mother and whether family receives benefit from social safety nets as a proxy of household economic status. Physical accessibility is another important determinant of healthcare choice in rural areas [46-47, 18, 10]. Availability, cost, quality and time required to receive the service are used to reflect this issue as these falls into the category of accessibility. It also includes the cost of service and the time required to reach the service providers.

\section{Results and Discussion}

The analysis starts with providing snapshot of the overall sample reported in figure 1 , which portrays the scenario of healthcare-seeking behavior in rural Bangladesh. 


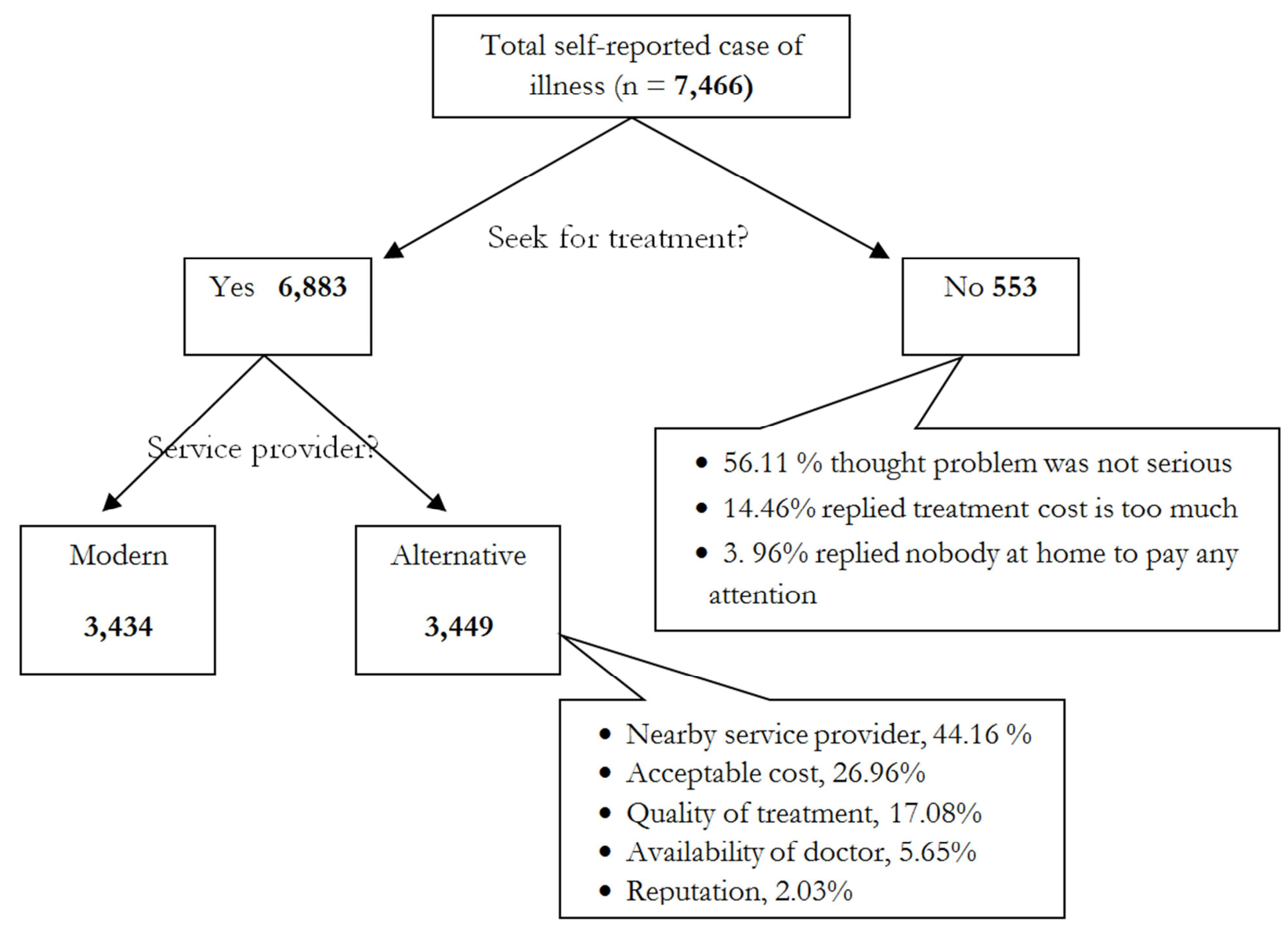

Figure 1. Healthcare-seeking behavior in rural Bangladesh.

Of the self-reported illness $(7,436)$, about $92 \%$ patients (i.e., 6,883$)$ seek treatment either from modern or alternative practitioners and it is the same size that helps to analyze the determinants of healthcare-seeking behavior and the extent of out-of-pocket payment scenario in rural Bangladesh. Figure 1 shows that $49.89 \%$ and $50.11 \%$ of the healthcare-seeking patients receive modern and alternative healthcare respectively. Therefore, a substantial number of patients are not choosing modern healthcare service as their $1^{\text {st }}$ preference. Easy accessibility of the service provider $(44.16 \%)$ and affordable cost $(26.96 \%)$ are the two major reasons for choosing alternative provides. $7.81 \%$ patients do not seek any treatment because of the two reasons: lack of awareness $(56.11 \%)$ and the cost beyond their capacity (14.46\%). In contrast, quality treatment is the most important reason of choosing modern treatment (Table 2).

\subsection{Treatment Choice}

Table 1 shows the distribution of healthcare-seeking patients by modern and alternative service providers. It shows that healthcare from private facility $(24.58 \%)$ and pharmacy $(41.14 \%)$ are the two major health service providers for the modern and alternative respectively. Reasons for choosing modern and alternative service are reported in table 2 which shows that easy access (42.91\%) and low cost $(26.56 \%)$ are the main reasons for choosing alternative healthcare. In contrast, quality of care $(42.89 \%)$ is the main reason for choosing modern healthcare.

Table 1. Choice of Service Provider.

\begin{tabular}{|c|c|c|c|c|c|}
\hline Modern & & & Alternative & & \\
\hline Provider & $\mathbf{n}$ & $\%$ & Provider & $\mathbf{N}$ & $\%$ \\
\hline Govt. Health Worker & 181 & 2.63 & Homeopath & 238 & 3.46 \\
\hline NGO Health Worker & 24 & 0.35 & Ayurved/Kabiraji/Hekim & 75 & 1.09 \\
\hline Govt. Doctor (govt. facility) & 602 & 8.75 & Traditional/Spiritual/Faith Healer & 22 & 0.32 \\
\hline Govt. Doctor (private facility) & 921 & 13.38 & Salesman of a Pharmacy/Dispensary & 2,832 & 41.14 \\
\hline Doctor from NGO facility & 14 & 0.2 & Family treatment & 61 & 0.89 \\
\hline \multirow[t]{2}{*}{ Doctor from Private facility } & 1,692 & 24.58 & Self-treatment & 37 & 0.54 \\
\hline & & & Other & 184 & 2.67 \\
\hline
\end{tabular}


Table 2. Reason for choosing the service provider.

\begin{tabular}{lllll}
\hline \multirow{2}{*}{ Reason for choosing the provider } & \multicolumn{2}{l}{ Modern } & \multicolumn{2}{l}{ Alternative } \\
\cline { 2 - 5 } & $\mathbf{n}$ & $\mathbf{\%}$ & $\mathbf{N}$ & $\mathbf{\%}$ \\
\hline Nearby & 756 & $22.02 \%$ & 1,480 & $42.91 \%$ \\
Acceptable cost & 556 & $16.19 \%$ & 916 & $26.56 \%$ \\
Availability of doctor & 280 & $8.15 \%$ & 198 & $5.74 \%$ \\
Availability of female doctor & 18 & $0.52 \%$ & 4 & $0.12 \%$ \\
Availability of equipment & 27 & $0.79 \%$ & 12 & $0.35 \%$ \\
Quality of treatment & 1,473 & $42.89 \%$ & 646 & $18.73 \%$ \\
Referred by other provider & 14 & $0.41 \%$ & 16 & $0.46 \%$ \\
Referred by relatives/friends & 34 & $0.99 \%$ & 32 & $0.93 \%$ \\
Reputation & 229 & $6.67 \%$ & 71 & $2.06 \%$ \\
Other & 47 & $1.37 \%$ & 74 & $2.15 \%$ \\
Total & 3,434 & $100 \%$ & 3,449 & $100 \%$ \\
\hline
\end{tabular}

\subsection{Self-Reported Illness and Treatment Choice}

There are seven broad categories of the self-reported illnesses, which are: i) water borne diseases (i.e., diarrhea, dysentery, typhoid and jaundice); ii) fever (though it's a symptom of a number of diseases but following the questionnaire this study puts it as a separate category); iii) infectious diseases (i.e., tuberculosis, malaria, scabies, leprosy); iv) traumatic diseases (i.e., pain, injury and weakness); v) cardiovascular and respiratory diseases (i.e., breathing trouble, pneumonia, heart diseases, blood pressure, hypertension); vi) disease of nervous system (dizziness, epilepsy and paralysis) and vii) systemic diseases (kidney diseases, gall stone, female and pregnancy related diseases and cancer).Table 3 shows that fever is the most prevalent disease and the patients with fever usually seek treatment more from alternative provider $(56.45 \%)$ than that of the modern $(43.55 \%)$. First-difference estimate is also statistically significant $\left(\chi^{2}=138.72\right)$ even at $1 \%$ level of significance. Similar finding is also observed for infectious diseases like tuberculosis, malaria, scabies and leprosy, but first-difference estimate is statistically insignificant $\left(\chi^{2}=0.1337\right)$. However, severe diseases like cardiovascular, nervous system related or systemic diseases, a significant portion of the patients (above $35 \%$ for each category) receive alternative care. Therefore, underutilization of modern healthcare is also evident for severe diseases in rural Bangladesh.

Table 3. Self-reported illness types and healthcare-seeking behavior.

\begin{tabular}{llllll}
\hline \multirow{2}{*}{$\begin{array}{l}\text { Broad categories of } \\
\text { diseases }\end{array}$} & \multicolumn{2}{l}{ Modern } & \multicolumn{2}{l}{ Alternative } & Significance $\left(\chi^{2}\right)$ \\
\cline { 2 - 6 } & $\mathbf{n}(\mathbf{1})$ & $\mathbf{\%}$ & $\mathbf{n ( 2 )}$ & $\mathbf{\%}$ & $\mathbf{n ( 1 ) ~ v s .} \mathbf{n}(\mathbf{2})$ \\
\hline Water Borne Diseases & 351 & 53.51 & 305 & 46.49 & $3.7905^{*}$ \\
Fever & 1,736 & 43.55 & 2,250 & 56.45 & $138.72^{* * *}$ \\
Infectious Diseases & 80 & 48.48 & 85 & 51.52 & 0.1337 \\
Traumatic Diseases & 591 & 57.71 & 433 & 42.29 & $29.455^{* * *}$ \\
CVRD $^{1}$ & 284 & 65.74 & 148 & 34.26 & $46.317^{* * *}$ \\
Disease of Nervous & 74 & 61.16 & 47 & 38.84 & $6.253^{* *}$ \\
System & & & & & \\
Systemic Diseases & 318 & 63.73 & 181 & 36.27 & $41.199 * * *$ \\
No. of observations & 3,434 & & 3,449 & & \\
\hline
\end{tabular}

Note: ${ }^{1}$ implies cardio vascular and respiratory disease; ${ }^{* * *} \mathrm{p}<0.01$, ${ }^{* *}$ $\mathrm{p}<0.05, * \mathrm{p}<0.1$

\subsection{Out-of-Pocket Payment for Healthcare}

The mean out-of-pocket (OOP) payment for healthcareseeking from modern and alternative healthcare is reported in table 4, which shows that the sum OOP for modern healthcare is significantly higher compared to the alternative. Disaggregate data show that charges for categories such as visit, hospital, medicine, diagnosis, transportation, tips and other miscellaneous service is relatively expensive for the modern compared to alternative. The difference estimates are statistically significant except for one category (i.e., tips). Total time required to reach the service provider can also be treated as a cost and we see that reaching to the modern healthcare center takes twice the time required for the alternative.

Table 4. Out-Of-Pocket Payment for modern and alternative healthcare.

\begin{tabular}{|c|c|c|c|}
\hline $\begin{array}{l}\text { PART A: Difference in OOP } \\
\text { by items (in } \mathrm{BDT}^{2} \text { ) }\end{array}$ & Modern & Alternative & Difference \\
\hline Visit & 84.67 & 15.69 & $68.98 * * *$ \\
\hline Hospital charge & 105.66 & 20.53 & $85.13 * *$ \\
\hline Medicine & 765.88 & 237.58 & $528.29 * * *$ \\
\hline Test (diagnosis) & 144.24 & 20.69 & $123.55 * * *$ \\
\hline Transportation & 82.22 & 15.05 & $67.17 * * *$ \\
\hline Tips & 27.99 & 1.38 & 26.62 \\
\hline Others & 57.30 & 6.55 & $50.75 * * *$ \\
\hline Total OOP & 1373.72 & 256.94 & $1116.78 * * *$ \\
\hline $\begin{array}{l}\text { Total time reach to the service } \\
\text { provider (in minutes) }\end{array}$ & 45.98 & 22.164 & $\begin{array}{l}23.81871 \\
* * *\end{array}$ \\
\hline \multicolumn{4}{|c|}{ PART B: Difference in OOP by diseases } \\
\hline Water Borne Diseases & 1304.97 & 382.99 & $921.98 * * *$ \\
\hline Fever & 539.32 & 175.30 & $364.01 * * *$ \\
\hline Infectious Diseases & 846.59 & 270.91 & $575.68 * * *$ \\
\hline Traumatic Diseases & 1457.49 & 340.60 & $1116.89 * * *$ \\
\hline $\begin{array}{l}\text { Cardio Vascular and Respiratory } \\
\text { Diseases }\end{array}$ & 4127.89 & 446.82 & 3681.08 \\
\hline Diseases of Nervous System & 2827.08 & 920.32 & 1906.76 \\
\hline Systemic Diseases & 3183.72 & 525.13 & $2658.59 * * *$ \\
\hline \multicolumn{4}{|c|}{ PART C: Difference in OOP by quintiles (in BDT) } \\
\hline Poorest & 1056.35 & 223.79 & $832.57 * * *$ \\
\hline $2^{\text {nd }}$ & 934.74 & 194.41 & $740.33^{* * *}$ \\
\hline $3^{\text {rd }}$ & 1048.33 & 239.85 & $808.48^{* * *}$ \\
\hline $4^{\text {th }}$ & 1128.64 & 310.50 & $818.15^{* * *}$ \\
\hline Richest & 2528.29 & 336.29 & $2192 * * *$ \\
\hline
\end{tabular}

Note: ${ }^{2}$ implies Bangladeshi Taka; ${ }^{* * *} \mathrm{p}<0.01,{ }^{* *} \mathrm{p}<0.05,{ }^{*} \mathrm{p}<0.1$

As healthcare cost also depends on the type of diseases $[14,27,48,38]$, disease-specific costing reported in table 4 shows that first-difference estimates are positive for all diseases (i.e., cost for modern> cost for alternative) and most of them are statistically significant. Similar findings are also observed in case of applying distributional perspective using quantiles. The mean difference in OOP between modern and alternative healthcare is the highest for the richest quantile.

\subsection{Healthcare-Seeking Behavior, Out-of-Pocket Payment and Time Cost by Quintiles}

Table 5 and the Annex Table A1 present the key healthcare 
related variables as well as predisposing and enabling factors respectively. Table 5 shows that receiving treatments from modern and alternative move to the opposite direction. The variations in the utilization of modern and alternative healthcare are highly statistically significant $\left(\chi^{2}=48.79\right.$ and $\mathrm{p}<0.001)$. Total time required reaching to the service provider increases as we move from the poorest to the lowest quintile. Mean expenditure for healthcare gradually increases from poorest to richest quintile (except the $2^{\text {nd }}$ quintile). The average treatment cost for the poorest quintile is BDT 589.65 whereas for the richest quintile it is BDT 1548.58. Variation in OOP variation across the quintiles is also statistically significant at $1 \%$ level of significance $(\mathrm{F}=5.31$ and $\mathrm{p}<0.001)$. In addition to these findings, a large share of poor people's consumption expenditure is contributed to healthcare and the burden of OOP gradually decreases as economic status improves.

Table 5. Key healthcare variables by quintiles.

\begin{tabular}{llllllll}
\hline Health care related Variable & Poorest & $\mathbf{2}^{\text {nd }}$ & $\mathbf{3}^{\text {rd }}$ & $\mathbf{4}^{\text {th }}$ & Richest & Observations & \multicolumn{1}{l}{$\boldsymbol{\chi}^{2} / \mathbf{A N O V A}$} \\
\hline Service & Modern (\%) & 17.65 & 18.55 & 20.38 & 21.26 & 22.16 & 3,434 \\
Provider & Alternate (\%) & 22.41 & 21.43 & 19.60 & 18.73 & 17.83 & 3,449 \\
Health Exp. (BDT) & & 589.66 & 537.13 & 651.14 & 744.54 & $1,548.58$ & 6,883 \\
Time required to reach the provider (Minutes) & 31.99 & 28.92 & 32.40 & 35.72 & 41.21 & 6,883 \\
\hline
\end{tabular}

Note: $* * * \mathrm{p}<0.01, * * \mathrm{p}<0.05, * \mathrm{p}<0.1$

Findings reported in the Annex table A1 shows the distribution of the mean values of the predisposing and enabling factors across the quintiles. We start with the former one. The mean age of the patients in the poorest quintile is 24.13. It shows that age of the patients is positively associated with economic status and the variations in age across the quintiles are statistically significant (i.e., $\mathrm{F}=36.02$ $\& \mathrm{p}<0.001)$. the notable difference in the sex of the patients exists only in the richest quintile, where percentage of female patient is much higher than their counterpart. However, overall variations in their percentage are also highly statistically significant (i.e., $\chi^{2}=5.81 * * *$ ). Of the female patients, the poorest quintile contains the lowest share of female patients $(19.67 \%)$ and the reverse is true for the richest quintile (21\%). This finding also supports the literature that poor women relatively less seek for healthcare. In case of $10.86 \%$ non-Muslim patients, the percentage share of the patients declines as the economic status goes up. The reverse scenario is true for the remaining Muslim patients. As per standard literacy rate (i.e., who can read and write) only $39.86 \%$ patients are literate and the literacy rate gradually increases with the improvement in economic status. There are significant variations in the difference between literacy and no literacy $\left(\chi^{2}=141.79 * * *\right)$. Regarding patent's literacy, $40 \%$ of the patient's mothers are literate and $44 \%$ of the family household heads are literate. The richest quintile contains the highest share of literate mothers and literate household heads (i.e., $25.13 \%$ and $25.51 \%$ respectively). Mother's level of education measured in years of schooling is relatively low for all quintiles and it remains up to the primary level. Same is true for household head's education level. Both household size and household density (members per living room) gradually decreases from poorest to richest quintile. The average household size for the poorest quintile is 5.69 whereas it is 4.59 for the richest quintile. Household density also decreases from 3.44 to 1.91 members per room as we move from the poorest to the richest quintile. Richest quintile also contains the largest share of household who have separate dining room (35.81\%) though it is only $10 \%$ for the full sample. This study finds that access to electricity, improved sanitary toilet (i.e., sanitary, water seal or pit) and safe drinking water are $42 \%, 43 \%$ and $91 \%$ sample households. Again, the richest quintile also contains the largest share of household who have access to electricity, improved sanitation facility and safe water. No variations in the access to water are found in this study. On the other hand, about 59\% households possess a mobile phone and the richest quintile contains the largest share $(25.89 \%)$ which is also expected.

Now it is checked how enabling factors (earning status, land holding, social benefits) are linked with economic status. It is about $25 \%$ of the patients are earner and about $7.7 \%$ patient's mother are earner. The richest quintile contains most of the patients who are earner, but the poorest quintile contains the largest share of earning mother (25.05\%). The poorest quintile also contains the largest share of household heads who receive benefit from social safety nets (SSN). This is expected as the program is designed to target this group. A wide inequality is found for landholdings among the poorest and richest quintiles as the poorest quintile holds on average 55.54 decimal of land whereas it is 145.35 decimal for the richest quintile. The variations in landholdings holds across the board.

Table 6. Regional variation in sickness by food consumption quintiles.

\begin{tabular}{|c|c|c|c|c|c|c|c|c|}
\hline Regions by & & Poorest & 2nd & 3rd & $4^{\text {th }}$ & Richest & Total & $\chi^{2} /$ ANOVA \\
\hline \multirow{2}{*}{ Barisal } & Yes & 27.90 & 19.00 & 14.93 & 18.70 & 19.46 & 663 & \multirow{2}{*}{$\chi^{2}=33.138 * * *$} \\
\hline & otherwise & 19.20 & 20.10 & 20.53 & 20.13 & 20.05 & 6,220 & \\
\hline \multirow{2}{*}{ Chittagong } & Yes & 12.55 & 16.34 & 17.66 & 22.77 & 30.67 & 1,291 & \multirow{2}{*}{$\chi^{2}=156.205^{* * *}$} \\
\hline & otherwise & 21.76 & 20.83 & 20.53 & 19.35 & 17.53 & 5,592 & \\
\hline \multirow{2}{*}{ Dhaka } & Yes & 20.94 & 22.86 & 20.75 & 17.60 & 17.85 & 1,557 & \multirow{2}{*}{$\chi^{2}=20.059 * * *$} \\
\hline & otherwise & 19.77 & 19.15 & 19.77 & 20.69 & 20.62 & 5,326 & \\
\hline Khulna & Yes & 23.17 & 21.25 & 22.91 & 17.42 & 15.24 & 1,148 & $\chi^{2}=33.815 * * *$ \\
\hline
\end{tabular}




\begin{tabular}{|c|c|c|c|c|c|c|c|c|}
\hline Regions by division & & Poorest & 2nd & 3rd & $4^{\text {th }}$ & Richest & Total & $\chi^{2} /$ ANOVA \\
\hline \multirow{3}{*}{ Rajshahi } & Otherwise & 19.41 & 19.74 & 19.41 & 20.51 & 20.94 & 5,735 & \multirow{3}{*}{$\chi^{2}=2.525$} \\
\hline & Yes & 19.64 & 18.75 & 21.76 & 20.09 & 19.75 & 896 & \\
\hline & Otherwise & 20.09 & 20.18 & 19.73 & 19.98 & 20.03 & 5,987 & \\
\hline \multirow{2}{*}{ Rangpur } & Yes & 22.36 & 19.75 & 21.74 & 21.49 & 14.66 & 805 & \multirow{2}{*}{$\chi^{2}=17.874 * * *$} \\
\hline & Otherwise & 19.73 & 20.02 & 19.76 & 19.79 & 20.70 & 6,078 & \\
\hline \multirow{2}{*}{ Sylhet } & Yes & 16.06 & 21.41 & 17.78 & 25.05 & 19.69 & 523 & \multirow{2}{*}{$\chi^{2}=13.681 * * *$} \\
\hline & Otherwise & 20.36 & 19.87 & 20.17 & 19.58 & 20.02 & 6,360 & \\
\hline
\end{tabular}

Table 6 shows the regional/geographical variations in sickness. The distribution of patients by regions shows that $9.63 \%, 18.76 \%, 22.62 \%, 16.68 \%, 13.02 \%, 11.70 \%$ and $7.60 \%$ patients are from Barisal, Chittagong, Dhaka, Khulna, Rajshahi, Rangpur and Sylhet divisions respectively. Therefore, the highest sickness is found in Dhaka and the lowest is in Sylhet. In Barisal, Khulna and Rangpur the poorest quintiles contain the highest share and it gradually declines as we move from poorest to richest quintile. In all cases (except Rajshahi) the variations in sicknesses are statistically significant at $1 \%$ level of significance. Finally, it could be concluded that no systematic variation exists in the sample.

\subsection{Analysis of Regression Results}

Annex table A2 shows the results using the probit regression model, where the dummy dependent variable is the 'Modern' (i.e., $=1$ if patients receives modern service and 0 , otherwise) and the explanatory variables are the predisposing and enabling factors. The objective is to measure the marginal effects of the determinants on the probability of choosing modern treatment and at the same time, variations in marginal effects across the quintiles are also explored.

Column 1 shows the results using the full sample and columns 2-6 show the quintile-wise regression results (i.e., starting from the poorest to the richest quintile). Results reported in column 1 shows that predisposing factors like patient's age, mother's age, mother's literacy and head's literacy are positively associated with the probability of choosing modern healthcare. No gender biasness in treatment choice is found in this study as the sign of the dummy variable sex of the patient (=1 if female) is positive but statistically insignificant. Muslim patients are more likely to visit modern service provider $(\mathrm{p}<0.001)$ compared to others. On the other hand, household head's age is less likely to visit modern practitioners $(\mathrm{p}<0.05)$. The rationales behind the choice of alternative healthcare are the lack of education of the elderly household and lack of their concern towards modern practitioners. Household size is positively associated with the probability of choosing treatment from modern services, which is negatively associated with household density. The latter one is expected as more people living per room means the low-income status of the households who are expected less likely to visit modern service providers.

Economic characteristics of the household features such as owning separate dining, access to electricity and using mobile phone are positively associated with access to modern services and marginal effects are statistically significant at best 5\% level of significance. Among the other enabling factors, household heads receiving benefits from social safety nets is less likely for modern service. The magnitude of the marginal effects of landholding is very low though significant. This implies that more landholding in rural Bangladesh does not necessarily increase the likelihood of receiving treatment from the modern. The main problem lies in their attitudes or behaviors of receiving treatment. Though most of the literature shows that wealth index does have a positive association with utilization of modern services, this study shows that the effects of the factors are not uniformly associated with the probability of utilizing modern healthcare. Estimates using six regional dummies ${ }^{1}$ show that patients from all these regions are more likely, though marginal effects are not always statistically significant, to receive treatment at modern health facility.

Similar estimation process at different quintiles investigate how marginal effects of the determinants vary across the quintiles (i.e., column 2 to 6). Results show that patient's age is positively associated with probability of choosing modern provider in the poorest and $3^{\text {rd }}$ quintiles. Therefore, the higher the patient's age at the poorer quintiles, the more likely that the patients receive treatment at modern healthcare facility. However, the higher the mother's age at the richest two quintiles, the more likely that patients receive treatment at the modern. Literate mothers are more likely to visit modern practitioners though marginal effects are statistically significant at the poorest and $4^{\text {th }}$ quintiles. Literate heads belonging to the richest quintile are more likely to visit modern facility. Similarly, Muslim patients coming from the richest two quintiles visit modern healthcare facility more compared to their counterpart. Households with larger household size are more likely whereas households with more density are less likely to visit modern practitioners. In rural Bangladesh, the poorest of the extreme poor belong to the smallest household size and thus they are less likely to receive services from the modern. People living per room is used as an surrogate of economic status of the households and thus the larger the density, the poorer the households and therefore, they visit less to the modern. Access to electricity is positively associated with the probability of choosing modern treatment irrespective of the quintiles considered. Access to electricity is associated with economic status and the access to electronic media (TVs and radios). Therefore, households with electricity connection are better informed about treatment options which increases the probability of seeking treatment from the modern. If the household head is

1 Dhaka is treated as the reference category. 
an earner, the probability of choosing treatment from modern provider increases in the poorest quintile $(p<0.1)$. Household access to social safety net benefit is negatively associated with the probability in the lowest two quintiles $(p<0.001)$. therefore, safety nets do not necessarily improve the access of the ultra-poor to the modern healthcare. For observing geographical variations in the access to modern healthcare, Dhaka is treated as reference category. The results show that patients from all income group of Barishal, Khulna and Rajshahi division are more likely to seek modern treatment compared to Dhaka. The estimated marginal effects are statistically significant.

\section{Conclusion}

This study uses the national survey dataset to investigate the effects of predisposing and enabling factors in determining the treatment choice. As a part of methodology, descriptive statistics, bivariate analysis (ANOVA and Chisquare test) and regression analysis (probit model on modern healthcare utilization for the full sample as well as for each quintile) have been used for identifying the determinants of healthcare-seeking behavior in rural Bangladesh. It concentrates only on Bangladesh's rural households for analyzing the treatment choice (modern vs. alternative). Though government and NGOs are expanding their modern treatment facilities all over the country, majority of patients $(50.11 \%)$ choose alternative treatment options because of the easy access and affordable cost. But the alarming issue is to take healthcare from the salespersons or dispensers, who do not have any kind of formal or informal training in Bangladesh (with very few exceptions).

Investigating marginal effects of the determinants of modern healthcare we find that age of patients and mothers, literate parents, religion and household features like -having separate dining room, access to electricity and availability of mobile phone (i.e., predisposing factors) play positive and significant role in influencing modern healthcare. However, this study finds some contrasting findings, which show that enabling factors like earning status, land holding and access to social benefit do not have any significant effect on modern healthcare utilization. Most of the earning members in rural Bangladesh are day labor or self-employed in his/her marginal landholdings. In addition, they are not literate and not habituated in using modern healthcare. Therefore, it is important to introduce intervention (e.g. behavioral health education) in rural Bangladesh that will contribute to change their behavior for the utilization of modern healthcare. Most importantly, no gender biasness is evident is our study.

The average OOP payment for modern healthcare is significantly higher than the alternative. More specifically, visit, hospital, medicine, diagnosis, transportation, tips and other miscellaneous service is also relatively expensive for the modern compared to alternative. First-difference estimates are positive for all diseases (i.e., OOP for modern> OOP for alternative) and most of them are statistically significant. Similar findings are also observed in case of applying distributional perspective using quantiles. The mean difference in OOP between modern and alternative healthcare is the highest for the richest quantile.

The study finds that predisposing factors play more significant role than the enabling factors in determining the utilization of modern healthcare. Socio-economic indicators (e.g. parent's literacy, access to information) rather than income or wealth are playing the major role in the determination of treatment choice. Instead of using wealth index we consider measuring the marginal effects of the enabling factors separately. It shows that enabling factors do not have any significant positive effect on the utilization of modern services. There are significant variations in the marginal effects across different quintiles in terms of both directions and magnitudes. Sickness and utilization of modern healthcare vary significantly across divisions. This variation should be taken into consideration while constructing a national health policy for the country. The suggested policies include proving public health education and awareness intervention to rural people and providing formal education to the alternative treatment, specially of Salesman of a Pharmacy/Dispensary. More importantly, the suggestion of the findings is to enhance utilization of modern service with providing special attention to young mothers, elder household heads and religious minority groups. The future scope to deeper our analysis is to undertake study that would help to analyze capturing the need factors for each specific disease.

\section{List of Abbreviations}

$\begin{array}{ll}\text { HIES } & \text { Household Income and Expenditure Survey } \\ \text { OOP } & \text { Out-Of-Pocket Payment (OOP) } \\ \text { ANOVA } & \text { Analysis Of Variance } \\ \text { NGO } & \text { Non-government Organization } \\ \text { SSN } & \text { Social Safety Nets } \\ \text { BDT } & \text { Bangladeshi Taka } \\ \text { TV } & \text { Television } \\ \text { CVRD } & \text { Cardiovascular and Respiratory Disease }\end{array}$

\section{Appendix}

Table A1. Distribution of the predisposing and enabling factors across quintiles.

\begin{tabular}{lllllllll}
\hline Predisposing Factors & & Poorest & $\mathbf{2}^{\text {nd }}$ & $\mathbf{3}^{\text {rd }}$ & $\mathbf{4}^{\text {th }}$ & Richest & Total & $\boldsymbol{\chi}^{2} / \mathbf{A N O V A}$ \\
\hline Patient's age & & 24.1269 & 24.96366 & 26.73837 & 28.5923 & 32.99855 & 6883 & $\mathrm{~F}=36.02^{* * *}$ \\
Patient's sex & Female & 19.67 & 19.59 & 19.56 & 20.17 & 21.00 & 3,619 & $\chi^{2}=5.82 * * *$ \\
& Male & 20.44 & 20.44 & 20.47 & 19.79 & 18.87 & 3,264 & \\
Religion & Islam & 19.76 & 19.61 & 19.84 & 20.26 & 20.54 & 6,135 & $\chi^{2}=17.4912 * * *$ \\
Patient's literacy & Other & 22.33 & 23.13 & 21.26 & 17.78 & 15.51 & 748 & 2,744 \\
\hline
\end{tabular}




\begin{tabular}{|c|c|c|c|c|c|c|c|c|}
\hline Predisposing Factors & & Poorest & $2^{\text {nd }}$ & $3^{\text {rd }}$ & $4^{\text {th }}$ & Richest & Total & $\chi^{2} /$ ANOVA \\
\hline & No & 23.46 & 21.87 & 19.30 & 18.39 & 16.98 & 4,139 & \\
\hline Mother's age & & 36.2328 & 37.53052 & 37.96148 & 39.4484 & 41.18459 & 6883 & $\mathrm{~F}=33.40 * * *$ \\
\hline \multirow{2}{*}{ Mother's literacy } & Yes & 15.04 & 16.70 & 21.33 & 21.80 & 25.13 & 2,766 & \multirow{2}{*}{$\chi^{2}=155.32 * * *$} \\
\hline & No & 23.39 & 22.20 & 19.09 & 18.78 & 16.54 & 4,117 & \\
\hline Mother's education (in years) & & 1.78027 & 2.178052 & 2.713663 & 2.96657 & 3.592297 & 6883 & $\mathrm{~F}=56.10 * * *$ \\
\hline \multirow{2}{*}{ Head's sex } & Male & 20.71 & 19.80 & 20.10 & 19.93 & 19.45 & 6,030 & \multirow{2}{*}{$\chi^{2}=19.48 * * *$} \\
\hline & Female & 15.24 & 21.34 & 19.23 & 20.40 & 23.80 & 853 & \\
\hline Head's age & & 43.9652 & 45.34666 & 45.90044 & 47.43823 & 49.06323 & 6883 & $\mathrm{~F}=28.48 * * *$ \\
\hline \multirow{2}{*}{ Head's literacy } & Yes & 14.99 & 16.90 & 20.51 & 22.09 & 25.51 & 3,042 & \multirow{2}{*}{$\chi^{2}=191.15^{* * *}$} \\
\hline & No & 24.03 & 22.44 & 19.58 & 18.33 & 15.62 & 3,841 & \\
\hline Head's education (in years) & & 2.1240 & 2.385174 & 3.344477 & 3.485465 & 4.316134 & 6883 & $\mathrm{~F}=68.24 * * *$ \\
\hline Household size & & 5.69688 & 5.336483 & 5.147529 & 5.066134 & 4.59157 & 6883 & $\mathrm{~F}=52.54 * * *$ \\
\hline Density & & 3.44467 & 2.99256 & 2.733723 & 2.345309 & 1.918948 & 6883 & $\mathrm{~F}=258.47 * * *$ \\
\hline \multirow{2}{*}{ Separate dining room } & Yes & 8.99 & 13.84 & 14.55 & 26.82 & 35.81 & 701 & \multirow{2}{*}{$\chi^{2}=189.73^{* * *}$} \\
\hline & No & 21.29 & 20.69 & 20.61 & 19.22 & 18.20 & 6,182 & \\
\hline \multirow{2}{*}{ Access to safe water } & Yes & 19.91 & 19.96 & 20.04 & 20.05 & 20.04 & 6,323 & \multirow{2}{*}{$\chi^{2}=0.9530$} \\
\hline & No & 21.43 & 20.36 & 19.46 & 19.29 & 19.46 & 560 & \\
\hline \multirow{2}{*}{ Access to proper sanitation } & Yes & 13.90 & 16.65 & 19.66 & 21.91 & 27.87 & 3,021 & \multirow{2}{*}{$\chi^{2}=308.61 * * *$} \\
\hline & No & 24.83 & 22.60 & 20.25 & 18.49 & 13.83 & 3,862 & \\
\hline \multirow{2}{*}{ Access to electricity } & Yes & 11.32 & 17.85 & 20.02 & 23.89 & 26.92 & 2,897 & \multirow{2}{*}{$\chi^{2}=359.32 * * *$} \\
\hline & No & 26.37 & 21.55 & 19.97 & 17.16 & 14.95 & 3,986 & \\
\hline \multirow{2}{*}{ Availability of mobile phone } & Yes & 14.25 & 17.28 & 19.65 & 22.93 & 25.89 & 4,091 & \multirow{2}{*}{$\chi^{2}=424.848 * * *$} \\
\hline & No & 28.51 & 23.96 & 20.49 & 15.69 & 11.35 & 2,792 & \\
\hline \multicolumn{9}{|l|}{ Enabling Factors } \\
\hline \multirow{2}{*}{ Patient's earning status } & Yes & 18.72 & 19.13 & 20.77 & 20.36 & 21.01 & 1,709 & \multirow{2}{*}{$\chi^{2}=4.8073$} \\
\hline & No & 20.47 & 20.27 & 19.73 & 19.87 & 19.66 & 5,174 & \\
\hline \multirow{2}{*}{ Mother's earning status } & Yes & 25.05 & 19.02 & 19.02 & 21.47 & 15.44 & 531 & \multirow{2}{*}{$\chi^{2}=14.341^{* * *}$} \\
\hline & No & 19.62 & 20.07 & 20.07 & 19.87 & 20.37 & 6,352 & \\
\hline \multirow{2}{*}{ Benefit received from safety nets } & Yes & 23.44 & 24.06 & 19.35 & 17.89 & 15.27 & 1,297 & \multirow{2}{*}{$\chi^{2}=44.1613 * * *$} \\
\hline & No & 19.24 & 19.05 & 20.14 & 20.48 & 21.09 & 5,586 & \\
\hline Landholdings (in decimal) & & 55.5417 & 72.30887 & 83.76817 & 109.9695 & 145.3568 & 6883 & $\mathrm{~F}=76.35 * * *$ \\
\hline
\end{tabular}

Note: $* * * \mathrm{p}<0.01, * * \mathrm{p}<0.05, * \mathrm{p}<0.1$

Table A2. Regression results from modelling modern healthcare provider.

\begin{tabular}{|c|c|c|c|c|c|c|}
\hline \multirow{2}{*}{ VARIABLES } & \multirow{2}{*}{$\begin{array}{l}\text { (1) (Overall) } \\
\text { Modern } \\
\end{array}$} & \multirow{2}{*}{$\begin{array}{l}\text { (2) Poorest } \\
\text { Quintile }\end{array}$} & \multirow{2}{*}{ (3) $2^{\text {nd }}$ quintile } & \multirow{2}{*}{ (4) $3^{\text {rd }}$ quintile } & \multirow{2}{*}{ (5) $4^{\text {th }}$ quintile } & \multirow{2}{*}{$\begin{array}{l}\text { (6) Richest } \\
\text { Modern }\end{array}$} \\
\hline & & & & & & \\
\hline \multirow{2}{*}{ Patient's age (in years) } & $0.00116 * * *$ & $0.00169 * *$ & 0.00111 & $0.00192 * *$ & $-7.05 \mathrm{e}-05$ & 0.000443 \\
\hline & $(0.000372)$ & $(0.000802)$ & $(0.000867)$ & $(0.000888)$ & $(0.000848)$ & $(0.000843)$ \\
\hline \multirow{2}{*}{ Patient's sex (=1 if female) } & 0.0181 & -0.00645 & 0.0364 & -0.00834 & 0.0304 & 0.0592 \\
\hline & $(0.0150)$ & $(0.0344)$ & $(0.0333)$ & $(0.0342)$ & $(0.0342)$ & $(0.0361)$ \\
\hline \multirow{2}{*}{ Religion (=1 if Muslim) } & $0.0570 * * *$ & 0.0240 & -0.0161 & 0.0510 & $0.138 * * *$ & $0.129 * *$ \\
\hline & $(0.0216)$ & $(0.0465)$ & $(0.0456)$ & $(0.0464)$ & $(0.0500)$ & $(0.0568)$ \\
\hline \multirow{2}{*}{ Patient's education (in years) } & -0.00264 & -0.00460 & 0.00334 & -0.00511 & $-0.00790 *$ & -0.00343 \\
\hline & $(0.00198)$ & $(0.00499)$ & $(0.00456)$ & $(0.00465)$ & $(0.00423)$ & $(0.00423)$ \\
\hline \multirow{2}{*}{ Mother's age (in years) } & $0.00381 * *$ & 0.00534 & -0.00452 & 0.00106 & $0.0120 * * *$ & $0.00525^{*}$ \\
\hline & $(0.00151)$ & $(0.00385)$ & $(0.00316)$ & $(0.00374)$ & $(0.00351)$ & $(0.00317)$ \\
\hline \multirow{2}{*}{ Mother's literacy ( $=1$ if literate) } & $0.0456 * * *$ & $0.0846 * *$ & 0.0436 & 0.0355 & $0.112 * * *$ & 0.0104 \\
\hline & $(0.0167)$ & $(0.0366)$ & $(0.0376)$ & $(0.0375)$ & $(0.0401)$ & $(0.0400)$ \\
\hline \multirow{2}{*}{ Head's sex (=1 if male) } & -0.0133 & -0.0453 & -0.0377 & -0.0696 & 0.0466 & 0.0206 \\
\hline & $(0.0302)$ & $(0.0752)$ & $(0.0651)$ & $(0.0692)$ & $(0.0677)$ & $(0.0712)$ \\
\hline \multirow{2}{*}{ Household head's age (in years) } & $-0.00273 * *$ & -0.00168 & 0.00417 & -0.00410 & $-0.0102 * * *$ & -0.00234 \\
\hline & $(0.00134)$ & $(0.00345)$ & $(0.00277)$ & $(0.00330)$ & $(0.00310)$ & $(0.00275)$ \\
\hline \multirow{2}{*}{ Head's literacy (=1 if literate) } & $0.0678 * * *$ & 0.0484 & 0.0952 & -0.0197 & 0.0622 & $0.157 * * *$ \\
\hline & $(0.0255)$ & $(0.0608)$ & $(0.0601)$ & $(0.0586)$ & $(0.0568)$ & $(0.0571)$ \\
\hline \multirow{2}{*}{ Head's education (years) } & -0.00532 & -0.00311 & -0.0128 & 0.00235 & -0.00322 & -0.0103 \\
\hline & $(0.00333)$ & $(0.00844)$ & $(0.00865)$ & $(0.00749)$ & $(0.00734)$ & $(0.00689)$ \\
\hline \multirow{2}{*}{ Household size } & $0.0179 * * *$ & $0.0262 * * *$ & $0.0393 * * *$ & 0.00937 & $0.0267 * * *$ & 0.00230 \\
\hline & $(0.00370)$ & $(0.00868)$ & $(0.00942)$ & $(0.00858)$ & $(0.00884)$ & $(0.00903)$ \\
\hline \multirow{2}{*}{ Density (member/room) } & $-0.0199 * * *$ & $-0.0182 *$ & $-0.0209^{*}$ & -0.00169 & $-0.0379 * * *$ & $-0.0261 *$ \\
\hline & $(0.00524)$ & $(0.0103)$ & $(0.0121)$ & $(0.0115)$ & $(0.0134)$ & $(0.0152)$ \\
\hline \multirow{2}{*}{ Dining room (=1 if yes) } & $0.0474 * *$ & 0.00255 & 0.0783 & $0.105^{*}$ & -0.0281 & 0.0220 \\
\hline & $(0.0214)$ & $(0.0688)$ & $(0.0584)$ & $(0.0554)$ & $(0.0435)$ & $(0.0391)$ \\
\hline \multirow{2}{*}{ Safe water (=1if yes) } & 0.0329 & -0.000181 & -0.0600 & $0.141 * * *$ & $0.143 * *$ & -0.0511 \\
\hline & $(0.0241)$ & $(0.0518)$ & $(0.0532)$ & $(0.0529)$ & $(0.0611)$ & $(0.0532)$ \\
\hline \multirow{2}{*}{ Proper sanitation (=1 if yes) } & -0.0170 & $-0.0553^{*}$ & -0.00230 & $-0.0611^{*}$ & 0.0291 & 0.0173 \\
\hline & $(0.0143)$ & $(0.0331)$ & $(0.0328)$ & $(0.0331)$ & $(0.0336)$ & $(0.0323)$ \\
\hline
\end{tabular}




\begin{tabular}{|c|c|c|c|c|c|c|}
\hline \multirow{2}{*}{ VARIABLES } & \multirow{2}{*}{$\begin{array}{l}\text { (1) (Overall) } \\
\text { Modern }\end{array}$} & \multirow{2}{*}{$\begin{array}{l}\text { (2) Poorest } \\
\text { Quintile }\end{array}$} & \multirow{2}{*}{ (3) $2^{\text {nd }}$ quintile } & \multirow{2}{*}{ (4) $3^{\text {rd }}$ quintile } & \multirow{2}{*}{ (5) $4^{\text {th }}$ quintile } & \multirow{2}{*}{$\begin{array}{l}\text { (6) Richest } \\
\text { Modern }\end{array}$} \\
\hline & & & & & & \\
\hline \multirow{2}{*}{ Electricity connection (=1 if yes) } & $0.0677 * * *$ & $0.109 * * *$ & 0.0299 & $0.0654 * *$ & 0.0120 & $0.115^{* * *}$ \\
\hline & $(0.0141)$ & $(0.0345)$ & $(0.0324)$ & $(0.0318)$ & $(0.0321)$ & $(0.0318)$ \\
\hline \multirow{2}{*}{ Mobile phone (=1 if yes) } & $0.0293 * *$ & 0.0143 & -0.0153 & $0.0668 * *$ & 0.0214 & -0.000634 \\
\hline & $(0.0146)$ & $(0.0320)$ & $(0.0328)$ & $(0.0320)$ & $(0.0367)$ & $(0.0387)$ \\
\hline \multirow{2}{*}{ Patient's earning status ( $=1$ if earner) } & 0.00174 & 0.0191 & 0.00225 & -0.00195 & 0.0246 & -0.0141 \\
\hline & $(0.0197)$ & $(0.0452)$ & $(0.0447)$ & $(0.0452)$ & $(0.0441)$ & $(0.0466)$ \\
\hline Head's earning status (=1 if yes) & $(0.0250)$ & $(0.0582)$ & $(0.0537)$ & $(0.0606)$ & $(0.0523)$ & $(0.0593)$ \\
\hline \multirow{2}{*}{ Mother's earner status (=1 if yes) } & 0.0154 & -0.0186 & -0.0197 & 0.0625 & 0.0797 & 0.0167 \\
\hline & $(0.0261)$ & $(0.0575)$ & $(0.0584)$ & $(0.0610)$ & $(0.0556)$ & $(0.0652)$ \\
\hline \multirow{2}{*}{ Social Safety Nets (=1 if receivers) } & $-0.0423 * *$ & $-0.161 * * *$ & -0.0512 & 0.0251 & 0.0219 & -0.0361 \\
\hline & $(0.0166)$ & $(0.0352)$ & $(0.0351)$ & $(0.0381)$ & $(0.0391)$ & $(0.0412)$ \\
\hline \multirow{2}{*}{ Landholding (in decimal) } & $-0.000127 * * *$ & -0.000181 & $-0.000336 * * *$ & -0.000145 & $0.000228 * *$ & $-0.000204 * * *$ \\
\hline & $(4.49 \mathrm{e}-05)$ & $(0.000161)$ & $(0.000113)$ & $(0.000122)$ & $(0.000107)$ & $(7.77 \mathrm{e}-05)$ \\
\hline Time required (in minutes) & $(0.000470)$ & $(0.00127)$ & $(0.00111)$ & $(0.000911)$ & $(0.000706)$ & $(0.000589)$ \\
\hline \multirow{2}{*}{ Barisal Division } & $0.191 * * *$ & $0.131 * *$ & $0.166^{* * *}$ & $0.112 *$ & $0.170 * * *$ & $0.321 * * *$ \\
\hline & $(0.0238)$ & $(0.0519)$ & $(0.0570)$ & $(0.0613)$ & $(0.0569)$ & $(0.0404)$ \\
\hline \multirow{2}{*}{ Chittagong Division } & $0.144 * * *$ & -0.00794 & $0.226 * * *$ & $0.230 * * *$ & $0.169 * * *$ & 0.0648 \\
\hline & $(0.0195)$ & $(0.0530)$ & $(0.0453)$ & $(0.0428)$ & $(0.0428)$ & $(0.0427)$ \\
\hline \multirow{2}{*}{ Khulna Division } & $0.239 * * *$ & $0.264 * * *$ & $0.228 * * *$ & $0.187 * * *$ & $0.229 * * *$ & $0.305 * * *$ \\
\hline & $(0.0189)$ & $(0.0477)$ & $(0.0441)$ & $(0.0418)$ & $(0.0452)$ & $(0.0369)$ \\
\hline \multirow{2}{*}{ Rajshahi Division } & $0.240 * * *$ & $0.126^{* * *}$ & $0.238 * * *$ & $0.228 * * *$ & $0.277 * * *$ & $0.305 * * *$ \\
\hline & $(0.0191)$ & $(0.0487)$ & $(0.0468)$ & $(0.0423)$ & $(0.0405)$ & $(0.0369)$ \\
\hline \multirow{2}{*}{ Rangpur Division } & $0.0393 *$ & -0.0237 & $0.171 * * *$ & 0.0147 & -0.0374 & 0.0278 \\
\hline & $(0.0233)$ & $(0.0507)$ & $(0.0500)$ & $(0.0510)$ & $(0.0538)$ & $(0.0587)$ \\
\hline \multirow{2}{*}{ Sylhet Division } & 0.00428 & -0.0406 & -0.0336 & $-0.203 * * *$ & -0.00941 & $0.211 * * *$ \\
\hline & $(0.0267)$ & $(0.0654)$ & $(0.0571)$ & $(0.0637)$ & $(0.0604)$ & $(0.0501)$ \\
\hline Observations & 6,883 & 1,379 & 1,376 & 1,376 & 1,376 & 1,376 \\
\hline
\end{tabular}

Note: Robust standard errors in parentheses; *** $\mathrm{p}<0.01, * * \mathrm{p}<0.05, * \mathrm{p}<0.1$

\section{References}

[1] Gwatkin, D. R., Rutstein, S., Johnson, K., Suliman, E., Wagstaff, A., \& Amouzou, A. (2007). Socio-economic differences in health, nutrition, and population within developing countries. Washington, DC: World Bank, 287.

[2] Gwatkin, D. R., Bhuiya, A., \& Victora, C. G. (2004). Making health systems more equitable. The Lancet, 364(9441), 1273 1280 .

[3] Victora, C. G., Wagstaff, A., Schellenberg, J. A., Gwatkin, D., Claeson, M., \& Habicht, J. P. (2003). Applying an equity lens to child health and mortality: more of the same is not enough. The Lancet, 362(9379), 233-241.

[4] Wagstaff, A. (2002). Poverty and health sector inequalities. Bulletin of the world health organization, 80, 97-105.

[5] Ahmed, S. M. (2009). Capability development among the ultra-poor in Bangladesh: a case study. Journal of health, population, and nutrition, 27(4), 528.

[6] Ahmed, S. M., Alam, B. B., Anwar, I., Begum, T., Huque, R., \& Khan, J. A. (2017). Bangladesh health SystemReview: health Systems in Transition.

[7] World Health Organisation (2015). Bangladesh: Health profile.

[8] Government of Bangladesh (2016). Health, nutrition and population strategic investment plan. Ministry of Health and Family Welfare, Dhaka, Bangladesh.

[9] Amin, R. (2007). Grameen Micro-credit to Grameen Kalyan
Health Program for the Poor, Reasons for Optimism. Academic Press and Publishers Library.

[10] Rahman, M. H., Mosley, W. H., Ahmed, S., \& Akhter, H. H. (2008). Does service accessibility reduce socioeconomic differentials in maternity care seeking? Evidence from rural Bangladesh. Journal of biosocial science, 40(1), 19-33.

[11] Amin, R., Shah, N. M., \& Becker, S. (2010). Socioeconomic factors differentiating maternal and child health-seeking behavior in rural Bangladesh: A cross-sectional analysis. International journal for equity in health, 9(1), 9.

[12] Karim, F., Tripura, A., Gani, M. S., \& Chowdhury, A. M. R. (2006). Poverty status and health equity: evidence from rural Bangladesh. Public health, 120(3), 193-205.

[13] Yunus, M. (2004). Grameen Bank, microcredit and millennium development goals. Economic and Political Weekly, 4077-4080.

[14] Ahmed, S. M., Adams, A. M., Chowdhury, M., \& Bhuiya, A. (2000). Gender, socioeconomic development and healthseeking behaviour in Bangladesh. Social science \& medicine, 51(3), 361-371

[15] Ahmed, S. M., Petzold, M., Kabir, Z. N., \& Tomson, G. (2006). Targeted intervention for the ultra poor in rural Bangladesh: Does it make any difference in their health-seeking behaviour?. Social science \& medicine, 63(11), 2899-2911.

[16] Koenig, M. A., Jamil, K., Streatfield, P. K., Saha, T., AlSabir, A., Arifeen, S. E.,... \& Haque, Y. (2007). Maternal health and care-seeking behavior in Bangladesh: findings from a national survey. International family planning perspectives, $75-82$. 
[17] Arifeen, S. E., Bryce, J., Gouws, E., Baqui, A. H., Black, R. E., Hoque, D. M. E.,... \& Siddique, A. (2005). Quality of care for under-fives in first-level health facilities in one district of Bangladesh. Bulletin of the World Health Organization, 83, 260-267.

[18] Chakraborty, N., Islam, M. A., Chowdhury, R. I., Bari, W., \& Akhter, H. H. (2003). Determinants of the use of maternal health services in rural Bangladesh. Health promotion international, 18(4), 327-337.

[19] Andersen, R. M. (1995). Revisiting the behavioral model and access to medical care: does it matter?. Journal of health and social behavior, 1-10.

[20] Andersen, R., \& Newman, J. F. (1973). Societal and individual determinants of medical care utilization in the United States. The Milbank Memorial Fund Quarterly. Health and Society, 95-124.

[21] Kroeger, A. (1983). Anthropological and socio-medical health care research in developing countries. Social science \& medicine, 17(3), 147-161.

[22] Carmel, S. (1990). The Health Belief Model in the research of AIDS-related preventive behavior. Public health reviews, 18(1), 73-85.

[23] Rahman, H. Z., \& Hossain, M. (1992). Rethinking rural poverty: a case for Bangladesh. Dhaka: Bangladesh Institute of Development Studies.

[24] Chrisman, N. J. (1977). The health seeking process: an approach to the natural history of illness. Culture, medicine and psychiatry, 1(4), 351-377.

[25] Ward, H., Mertens, T. E., \& Thomas, C. (1997). Health seeking behaviour and the control of sexually transmitted disease. Health Policy and planning, 12(1), 19-28.

[26] Zola, I. K. (1966). Culture and symptoms--an analysis of patient's presenting complaints. American sociological review, 615-630.

[27] Helman, C. G. (1995). The body image in health and disease: exploring patients' maps of body and self. Patient Education and Counseling, 26(1), 169-175.

[28] Kleinman, A., \& Gale, J. L. (1982). Patients treated by physicians and folk healers: a comparative outcome study in Taiwan. Culture, medicine and psychiatry, 6(4), 405-423.

[29] Timyan, J., SJ, G. B., Measham, D. M., \& Ogunleye, B. (1993). Access to care: more than a problem of distance.

[30] Chaudhury, N., \& Hammer, J. (2003). Ghost doctors: absenteeism in Bangladeshi health facilities. The World Bank.

[31] Jahan, R. (2007). Securing maternal health through comprehensive reproductive health services: lessons from Bangladesh. American journal of public health, 97(7), 11861190 .

[32] Anwar, A. T., Killewo, J., Chowdhury, M. K., \& Dasgupta, S. (2005). Bangladesh: Inequalities in utilization of maternal health care services-Evidence from Matlab. Reaching the poor with health, nutrition, and population services-what works, what doesn't, and why. Washington, DC: World Bank, 117-36.
[33] Perry, H. B. (2000). Health for all in Bangladesh: lessons in primary health care for the twenty-first century. University Press.

[34] Sen, B., \& Begum, S. (1998). Methodology for identifying the poorest at local level. In Macroeconomics: Health and Development Series.

[35] Ensor, T., Dave-Sen, P., Ali, L., Hossain, A., Begum, S. A., \& Moral, H. (2002). Do essential service packages benefit the poor? Preliminary evidence from Bangladesh. Health Policy and Planning, 17(3), 247-256.

[36] Wong, E. L., Popkin, B. M., Guilkey, D. K., \& Akin, J. S. (1987). Accessibility, quality of care and prenatal care use in the Philippines. Social Science \& Medicine, 24(11), 927-944.

[37] Becker, S., Peters, D. H., Gray, R. H., Gultiano, C., \& Black, R. E. (1993). The determinants of use of maternal and child health services in Metro Cebu, the Philippines. Health transition review, 77-89.

[38] Kleinman, A. (1980). Patiens and healers in the context of culture: An exploration of the borderland between anthropology, medicine, and psychiatry. Berkeley: University of California Press.

[39] Fosu, G. B. (1994). Childhood morbidity and health services utilization: cross-national comparisons of user-related factors from DHS data. Social science \& medicine, 38(9), 1209-1220.

[40] Costello, M. A., Lleno, L. C., \& Jensen, E. R. (1996). Determinants of two major early-childhood diseases and their treatment in the Philippines: findings from the 1993 National Demographic Survey. Asia-Pacific population research abstracts, (9), 1-2.

[41] Waldron, I. (1982). An analysis of causes of sex differences in mortality and morbidity. The fundamental connection between nature and nurture, 69-116.

[42] Gotsadze, G., Bennett, S., Ranson, K., \& Gzirishvili, D. (2005). Health care-seeking behaviour and out-of-pocket payments in Tbilisi, Georgia. Health policy and planning, 20(4), 232-242.

[43] Murray, C. J., \& Chen, L. C. (1992). Understanding morbidity change. The Population and Development Review, 481-503.

[44] SIAPS (2015). Baseline Study of Private Drug Shops in Bangladesh: Findings and Recommendations. US Agency for International Development. Arlington, VA: Management Sciences for Health.

[45] Mannan, M. A. (1990). Mother and child health in Bangladesh: evidence from field data.

[46] Stock, R. (1983). Distance and the utilization of health facilities in rural Nigeria. Social science \& medicine, 17(9), 563-570.

[47] Paul, B. K. (1991). Health service resources as determinants of infant death in rural Bangladesh: an empirical study. Social science \& medicine, 32(1), 43-49.

[48] Roberts, R. E. (1983). Medical Choice in a Mexican Village. 